\title{
A Three-Step Method for Estimating the Mixing Height Using Ceilometer Data from the Helsinki Testbed
}

\author{
NOORA ERESMAa, JARI HÄrKÖNEN, AND SylVAIN M. JOFFRE \\ Finnish Meteorological Institute, Helsinki, Finland
}

\section{DAVID M. SCHULTZ}

Finnish Meteorological Institute, and Division of Atmospheric Sciences, Department of Physics, University of Helsinki, Helsinki, Finland, and Centre for Atmospheric Science, School of Earth, Atmospheric and Environmental Sciences, University of Manchester, Manchester, United Kingdom

ARI KARPPINEN AND JAAKKO KUKKONEN

Finnish Meteorological Institute, Helsinki, Finland

(Manuscript received 22 February 2012, in final form 24 May 2012)

\begin{abstract}
A new three-step idealized-profile method to estimate the mixing height from vertical profiles of ceilometer backscattering coefficient is developed to address the weaknesses found with such estimates that are based on the one-step idealized-profile method. This three-step idealized-profile method fits the backscattering coefficient profile of ceilometer measurements into an idealized scaled vertical profile of three error functions, thus having the potential to determine three aerosol layers (one for the surface layer, one for the mixing height, and one for the artificial layer caused by the weakened signal). This three-step idealized-profile method is tested with ceilometer and radiosounding data collected during the Helsinki Testbed campaign (2 January 2006-13 March 2007). Excluding cases with low aerosol concentration in the boundary layer, cases with clouds present, and cases with precipitation present, the resulting dataset consists of 97 simultaneous backscattering coefficient profiles and radiosoundings. The three-step method is compared with the one-step method and other commonly employed algorithms. A strong correlation (correlation coefficient $r=0.91$ ) between the mixing heights as determined by the three-step method using ceilometer data and those determined from radiosoundings is an improvement over the same correlation using the one-step method $(r=$ $0.28)$, as well as the other algorithms.
\end{abstract}

\section{Introduction}

The turbulent properties of the atmospheric boundary layer (ABL) - such as the diffusivity, mixing, and transport-determine whether pollutants are dispersed and diluted or whether they build up and lead to pollution episodes. Thus, estimating, parameterizing, monitoring, and predicting the structure and behavior of the $\mathrm{ABL}$ is crucial to determining air quality. The ABL height or one of its proxies, the mixing height $(\mathrm{MH})$, determines the volume of $\mathrm{ABL}$ available for pollutant dispersal. Because the $\mathrm{MH}$ cannot be observed directly by standard measurements, it must be indirectly

Corresponding author address: Jari Härkönen, Finnish Meteorological Institute, PL503, 00101 Helsinki, Finland.

E-mail: jari.harkonen@fmi.fi estimated from profile measurements or parameterized from simulations. The most common methods for indirectly estimating the $\mathrm{MH}$ are based on data from radiosoundings, data from remote sensing systems (e.g., sodars, lidars, radars, ceilometers), and ABL parameterization methods (Seibert et al. 2000). Beyrich (1997) and Asimakopoulos et al. (2004) state that adequate MH determination from measurements must satisfy the following criteria:

1) Availability of vertical profiles of atmospheric parameters (e.g., temperature, humidity, wind, and backscattering profiles from remote sensing systems) between the ground and $2 \mathrm{~km}$;

2) high vertical resolution (10-30 m) of these profiles to resolve small-scale gradients in the vertical structure of atmospheric parameters; and 
3) time increments of $1 \mathrm{~h}$ or less to be able to describe the diurnal evolution of the ABL.

The earliest methods for determining the MH relied upon radiosoundings, although these data are too infrequent in space and time. Most recent studies rely on the better spatial and temporal resolution of remote sensing systems. One such remote sensing device is the ceilometer, which measures the vertical profile of the atmospheric optical backscattering coefficient (Münkel 2007).

This study investigates the suitability of ceilometer measurements to determine the MH. The backscattering coefficient depends mainly upon the backscattering of the radiation emitted from the ceilometer by the concentration and size distribution of particulates in the air. Because particulate concentrations are lower in the free atmosphere than in the ABL, the top of the $\mathrm{ABL}$ can be distinguished in most cases as a strong gradient in the vertical profile of backscattering coefficient.

There are several approaches to estimate the height of this gradient. One of the simplest methods is the basic gradient method, in which the first or second derivative of the backscattering coefficient profile indicates the MH (e.g., Endlich et al. 1979; Sicard et al. 2006; Emeis et al. 2007). The strength of this method is its simplicity. In principle, the gradient is easy to find numerically, but, in reality, the backscattering coefficient profiles do not always follow the theoretical profile shape with only one strong gradient. Instead, the profiles are more complex with several gradients. Thus, choosing the "right" gradient for the MH contains some arbitrariness. Should the first gradient from the ground be chosen, or the strongest one? Haeffelin et al. (2011) present an insightful intercomparison between some gradient-based and wavelet algorithms for the evaluation of the MH.

Instead of this basic gradient method, some studies use the so-called idealized-profile method to estimate the MH from ceilometer measurements (e.g., Steyn et al. 1999; Hägeli et al. 2000; Eresmaa et al. 2006). This method removes some of the arbitrariness of the basic gradient method by instead finding the decrease in the backscattering coefficient profile. Unfortunately, the idealizedprofile method is inadequate to determine the $\mathrm{MH}$ in the case of multilayered backscattering coefficient profiles. Specifically, Hägeli et al. (2000) find the idealized-profile method generates negative MHs in some cases. Also, Eresmaa et al. (2006) find that high particulate concentrations in the surface layer lead to underestimates of the actual MH.

Therefore, this present work aims to improve upon the idealized-profile method by rendering it capable of detecting up to three aerosol layers. In this way, the improved profile method will be applicable for a larger variety of real-life backscattering coefficient profiles. The improved idealized profile includes the mathematically important assumption of cumulative distribution of the backscattered signals, which can provide an interpretation of the encountered gradients compared to the original idealized-profile method.

\section{Measurement campaigns and experimental methods}

In this study, the validation of MH values detected using ceilometer profiles is performed against $\mathrm{MH}$ values determined from radiosoundings. All our data are collected within the Helsinki Testbed, a mesoscale meteorological network in southern Finland (Fig. 1) in operation since 2005 (Koskinen et al. 2011; http://testbed. fmi.fi). In addition to an extensive network of surface weather stations, the Helsinki Testbed includes six ceilometers in an area of $50 \mathrm{~km} \times 50 \mathrm{~km}$ and one radiosounding site, thus providing near-simultaneous ceilometer and radiosounding measurements. This section describes the Helsinki Testbed and the data (section 2a) and the technical specifications of the ceilometer (section 2b).

\section{a. The measurement campaigns}

The Helsinki Testbed is a mesoscale observing system and research program with the aim to improve observing systems and networks, understanding of weather phenomena important to Finland, and modeling on the regional and urban scales (Koskinen et al. 2011). The domain of the Helsinki Testbed, approximately $150 \mathrm{~km} \times 150 \mathrm{~km}$, covers much of southern Finland and is centered upon Helsinki (Fig. 1), a metropolitan area of nearly one million inhabitants.

In this study, we use ceilometer and radiosounding data obtained within the Helsinki Testbed Project from 2 January 2006 to 13 March 2007. Of the 113 simultaneous noncloudy ceilometer and radiosounding measurements used in this study, most were collected during two special radiosounding campaigns: January-February 2006 (52 radiosoundings) focusing on the stable boundary layer and its dynamics, and August 2006 (41 radiosoundings) focusing on convection and lightning. The remaining 20 radiosoundings were collected outside of these intensive campaigns.

The radiosoundings were launched in Vantaanlaakso, approximately $15 \mathrm{~km}$ from the center of Helsinki (Fig. 1). The ceilometer observations were collected at two sites. The ceilometer was originally situated in Tikkurila during the January-February campaign, but was moved $10 \mathrm{~km}$ east to Vantaanlaakso (near the radiosounding launching site) for the August campaign. Both Tikkurila 


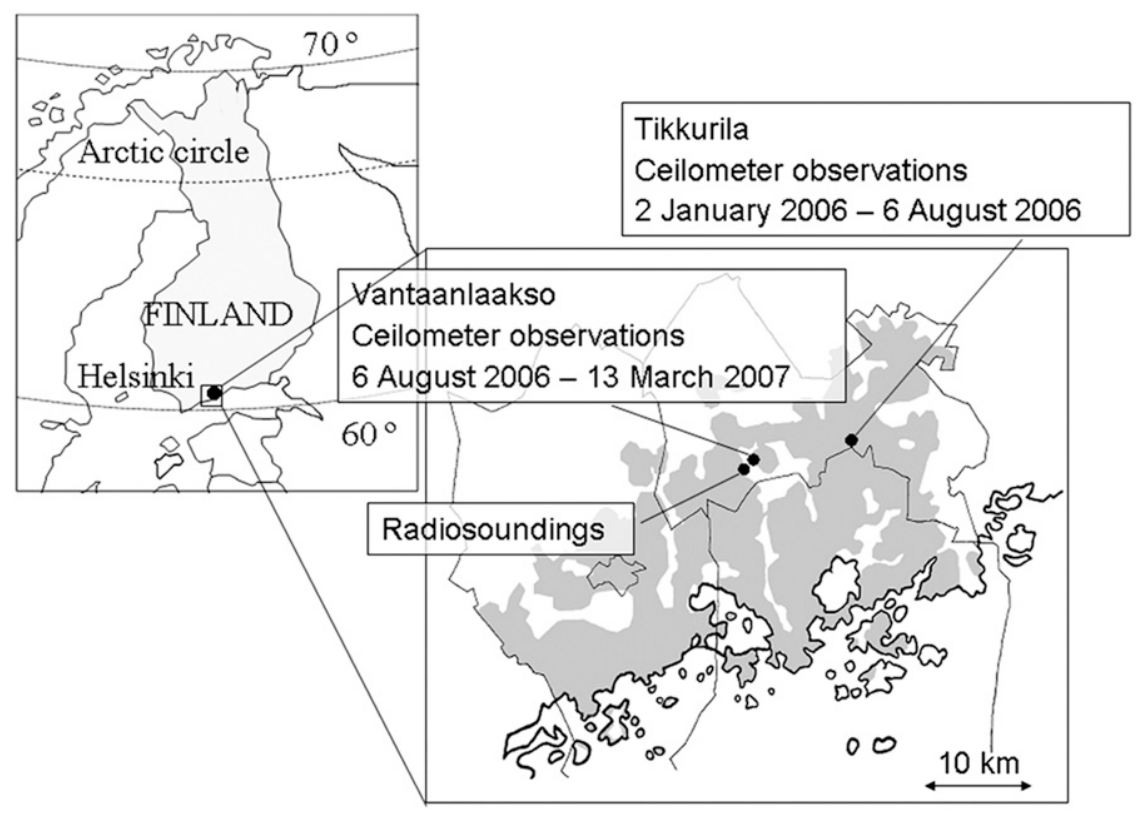

FIG. 1. Maps of (left) the location of Helsinki within Finland and (right) the locations of the observation sites Tikkurila and Vantaanlaakso within the Helsinki metropolitan area. The size of the depicted area is approximately $60 \mathrm{~km} \times 50 \mathrm{~km}$. The areas with the highest proportion of buildings relative to other land-use types are depicted in gray shading.

and Vantaanlaakso are suburban areas influenced by traffic pollution from the Helsinki metropolitan area. Both sites have similar suburban emission environments and meteorological conditions with the same distance to the sea. Most of the radiosoundings were launched during the night (1800-0300 UTC; local standard time $=$ $\mathrm{UTC}+2 \mathrm{~h}$ ), as shown in Fig. 2. In this study, we use only the Tikkurila-Vantaanlaakso ceilometer as it was the closest to the radiosounding site and had the longest measurement period.

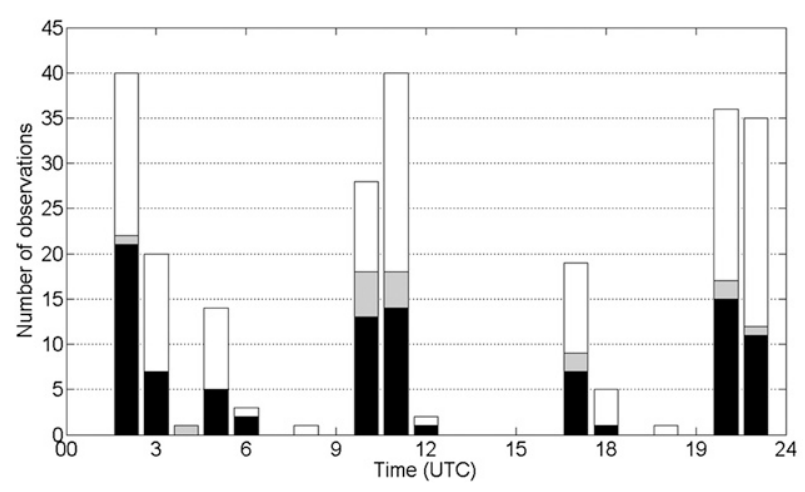

FIG. 2. Histogram of the launch times of the 245 radiosoundings: 132 were released with clouds present (white), 113 were released in the absence of clouds with 16 of them (gray) rejected (see reasons in the text), leaving 97 profiles in the final dataset used for this study (black).

\section{b. Technical characteristics of instrumentation}

The Vaisala ceilometer CL31, described by Münkel and Räsänen (2004) and Münkel et al. (2007), measures the optical backscatter intensity at a wavelength of $910 \mathrm{~nm}$ (near infrared). The CL31 has a laser with a single lens that collimates the outgoing beam. The returning signal from the backscattered radiation is focused onto the receiver by the outer part of the lens. A mirror situated at an oblique angle allows the transmitted beam to be separated from the returning beam (Münkel et al. 2007).

Table 1 lists the main technical specifications of the CL31 ceilometer (Vaisala 2006). For safety and economy, the laser power used is so low that the noise exceeds the backscattering signal. Summing over a large number of return signals improves the signal-to-noise ratio, although this processing gain cannot be extended ad infinitum in a changing environment. For this study,

TABLE 1. Technical specifications of the CL31 ceilometer (Vaisala 2006).

\begin{tabular}{ll}
\hline Measurement range & \multicolumn{1}{c}{$0-7500 \mathrm{~m}$} \\
\hline Resolution & $10 \mathrm{~m}$ (used in this project) or $5 \mathrm{~m}$ \\
Laser system & Indium gallium arsenide laser diode \\
Wavelength & $910 \pm 10 \mathrm{~nm}$ at $25^{\circ} \mathrm{C}$ \\
Pulse properties & $110 \mathrm{~ns}, 1.2 \mu \mathrm{J}$ per pulse \\
Mean pulse repetition & $8192 \mathrm{~Hz}$ \\
$\quad$ & \\
\hline
\end{tabular}


TABLE 2. Resolution and accuracy of the RS92 radiosonde as indicated by the manufacturer.

\begin{tabular}{lcc}
\hline \hline & Resolution & Accuracy \\
\hline Temperature & $0.1^{\circ} \mathrm{C}$ & $0.5^{\circ} \mathrm{C}$ \\
Relative humidity & $1 \% \mathrm{RH}$ & $5 \% \mathrm{RH}$ \\
Pressure & $1 \% \mathrm{hPa}$ & $1 \mathrm{hPa}$ \\
\hline
\end{tabular}

the raw ceilometer profiles are obtained every $16 \mathrm{~s}$ and are averaged every $15 \mathrm{~min}$.

The reference $\mathrm{MH}$ is determined by analyzing radiosounding data as described in section 3a. The resolution and accuracy of the Vaisala RS92 radiosonde used in this study are given in Table 2 .

\section{Computational methods}

In this section, we describe the methods for determining the $\mathrm{MH}$ from radiosounding (section 3a) and ceilometer backscattering coefficient profiles (section $3 b$ ).

\section{a. Methods for estimating the mixing height from radiosoundings}

To compare the MH estimates from ceilometer data, two traditional $\mathrm{MH}$ estimation methods are applied to radiosounding data depending upon the stability. The MH is estimated by the maximum height of the mixing if the sounding is unstable, whereas the equilibrium $\mathrm{MH}$ is used if the sounding is stable. The sounding is classified as unstable or stable based on the potential temperature $(\theta)$ profile from the radiosoundings. Specifically, if a superadiabatic surface layer between the lowest measurement level (approximately $40 \mathrm{~m}$ ) and $100 \mathrm{~m}$ is found, the case is considered unstable $(13 \%$ of cases). Otherwise, the case is considered stable ( $87 \%$ of cases). The larger number of stable cases is due to the timing of radiosonde launches with $85 \%$ of the radiosoundings being launched during nighttime. The large number of nighttime radiosonde launches provides a good opportunity to study the stable, shallow boundary layer heights, which are the most critical for air quality.

In unstable situations, radiosonde data can be used to estimate the MH by lifting a surface air parcel along the dry adiabat until its intersection with the actual temperature profile (Holzworth 1964, 1967). In this study, the initial temperature is not the surface temperature, but the mean temperature of the superadiabatic layer near the surface. The advantage of this method is its simplicity —only the temperature profile with height is needed. A disadvantage is that the MH may be sensitive to the details of the temperature profile in situations without a clear inversion at the top of the convective boundary layer (Seibert et al. 2000).
In stable situations, radiosonde data can be used to estimate the MH by calculating the Richardson number Ri (e.g., Vogelezang and Holtslag 1996):

$$
\operatorname{Ri}\left(z_{i+1}\right)=\frac{g}{T_{s}} \frac{\left(\theta_{i+2}-\theta_{i}\right)\left(z_{i+z}-z_{i}\right)}{\left(V_{i+2}-V_{i}\right)^{2}},
$$

where $g$ is the gravitational acceleration, $T_{s}$ is the nearsurface air temperature, $\theta_{i}$ is the potential temperature at the $i$ th layer of the profile, and $V_{i}$ is the wind speed at height $z_{i}$. This formula aims at smoothing out some of the inherent fluctuations between adjacent layers, especially those of the wind. To apply this method, the $\mathrm{MH}$ is located where $\mathrm{Ri}$ exceeds a fixed critical value, determining the equilibrium $\mathrm{MH}$ rather than the actual MH (Zilitinkevich and Baklanov 2002). In the present study, we use the Richardson number profile method of Joffre et al. (2001) with a critical Ri of 1.

\section{b. Methods for estimating the MH from ceilometer measurements}

Because the concentration of aerosols decreases rapidly with height from the top levels of the ABL into the free atmosphere, the $\mathrm{MH}$ can be characterized by a gradient in the backscattering coefficient as a function of height. Two approaches have been proposed to estimate the height of this gradient:

1) The basic gradient method, in which the minimum in the first or second derivative of the backscattered signal indicates the MH (e.g., Endlich et al. 1979; Sicard et al. 2006; Emeis et al. 2007).

2) The idealized-profile method, in which the $\mathrm{MH}$ is determined from an idealized profile fitted to the measured one (Steyn et al. 1999).

Besides these two gradient methods, standard deviation (STD) methods have also been used for $\mathrm{MH}$ estimation. Because the interface between the ABL and the free atmosphere is normally strongly convoluted (Hooper and Eloranta 1986), the advection of these convolutions causes a temporal variance in the backscattered signal. In such circumstances, the MH is defined as the height of the maximum variance. The variance maximizes at the MH because the variability is less below the MH in the ABL (the contrast between turbulent structures in the aerosol field is smaller) and the variability is less above the $\mathrm{MH}$ in the free atmosphere (the air is cleaner with fewer variations in backscattered signal).

In this paper, we focus on the idealized-profile method and compare our results with those from other methods. In the first part of section $3 \mathrm{~b}$, we discuss the original one-step 
method, whereas the three-step method, the main topic of this paper, is explained in the second part of section $3 b$. The basic gradient method and the STD method are discussed briefly in the third and fourth parts of section $3 \mathrm{~b}$.

\section{1) THE ONE-STEP IDEALIZED-PROFILE METHOD}

The one-step idealized-profile method evaluates not only the MH but also the thickness of the entrainment layer (Steyn et al. 1999). The entrainment layer is the layer where the $\mathrm{ABL}$ air and free atmosphere air mix together. In remote sensing measurements, the entrainment layer is usually defined to be the layer possessing $5 \%-95 \%$ of the characteristics of the free atmosphere, such as low aerosol concentrations (Nelson et al. 1989; Cohn and Angevine 2000).

In this method, a one-step idealized profile is fitted to the measured backscattering coefficient profile by the formula

$$
B(z)=\frac{B_{m}+B_{u}}{2}-\frac{B_{m}-B_{u}}{2} \operatorname{erf}\left(\frac{z-\mathrm{MH}}{\Delta h}\right)
$$

where the error function $\operatorname{erf}(x)$ is defined as $\operatorname{erf}(x)=$ $(2 / \sqrt{\pi}) \int_{0}^{x} e^{-t^{2}} d t, B_{m}$ is the mean mixing layer backscattering coefficient, $B_{u}$ is the mean backscattering coefficient in the layer above the $\mathrm{ABL}$, and $\Delta h$ is proportional to the entrainment layer thickness (ELT) capping the step, where ELT $=2.34 \Delta h$ (derived in the appendix).

The main advantage of the one-step idealized-profile method relative to the basic gradient methods is its ability to account for the whole backscattering coefficient profile. One of the disadvantages of the idealized-profile method is that the measured profile of backscattering coefficient may include some occasional sharp gradients within the ABL that can lead to false estimates of the MH (Steyn et al. 1999). Thus, the one-step idealized profile is incapable of distinguishing the surface layer from the mixed layer, which often appear as two separate layers in the backscattering coefficient profile. Consequently, the one-step method is unable to evaluate reliably the $\mathrm{MH}$ in such conditions (Eresmaa et al. 2006).

\section{2) THE THREE-STEP IDEALIZED-PROFILE METHOD}

As the one-step method is unable to evaluate the $\mathrm{MH}$ in a case of two or more aerosol layers, the original method has been revised and developed into a threestep version of the idealized profile. The measured backscattering coefficient $\left(\mathrm{m}^{-1} \mathrm{sr}^{-1}\right)$ as a function of height increases from the free atmosphere to the ground surface (Fig. 3). However, three steps $(i=1,2,3)$ are apparent in the profiles, where $B_{i}$ represents the backscattering

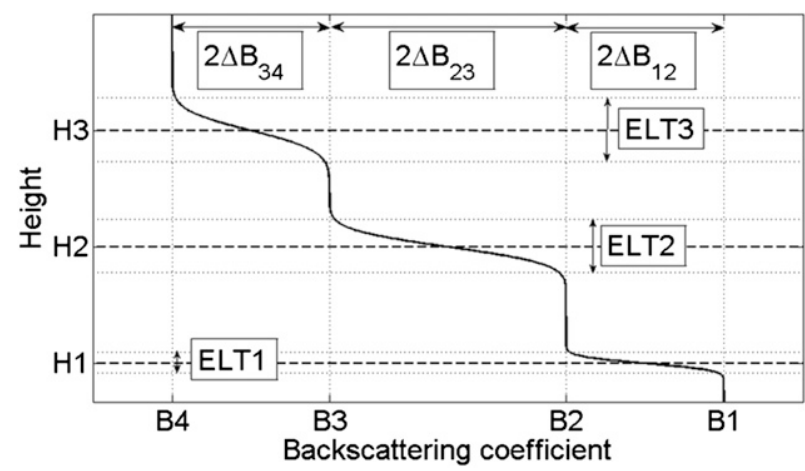

FIG. 3. A schematic illustration of the three-step idealized profile of backscattering coefficient. The ELT is calculated using the definition of Steyn et al. (1999). The scaling factor $\Delta B_{i j}$ is defined from Eq. (3a).

coefficient at average step height $H_{i}$ and the entrainment layer thickness $\mathrm{ELT}_{i}$ is defined by Steyn et al. (1999). The two lowest layers illustrate the surface layer and the mixed layer, whereas the third and uppermost layer aims to make the fitting more robust. Typically, the third layer is caused by attenuation of the signal or noise.

Extending the approach of Steyn et al. (1999) from one to several normally distributed aerosol layers in the lower atmosphere, we present the idealized profile of the backscattering coefficient as a linear combination of complementary error functions $\operatorname{erfc}(x)=1-\operatorname{erf}(x)$. The appropriate scaling factors and constants can be solved from the measured data. We also define heights $h_{i}$, where $h_{1}$ is the lowest monitoring height of the ceilometer, $h_{2}$ and $h_{3}$ are located between layers 1 and 2, and 2 and 3 such that $H_{i-1}+\left(\mathrm{ELT}_{i-1} / 2\right)<h_{i}<H_{i}-\left(\mathrm{ELT}_{i} / 2\right)$ $(i=2,3)$, and $h_{4} \gg H_{3}$. This three-step idealized profile of backscattering coefficient is illustrated in Fig. 3. The denoted values of backscattering coefficient $B_{i}$ and average heights $H_{i}$ of the normal distributions have a key role in determining the values for scaling factors and constants of the fitting.

When a backscattering coefficient profile is approximated by a continuous probability density function producing a cumulative distribution, it is reasonable to assume that the backscattered signal comes from a finite height interval. Using the notations in Fig. 3, the following conditions must be fulfilled in the case of three steps: $B\left(h_{1}\right)=B_{1}, B\left(h_{4}\right)=B_{4}$, and $B\left(H_{i}\right)=\left(B_{i}+B_{i+1}\right) /$ 2 , for $i=1,2,3$. The mean backscattering coefficient from the lowest measurement level is $B_{1} ; B_{2}$ and $B_{3}$ are the mean backscattering coefficients between steps 1 and 2, and steps 2 and 3, respectively; and $B_{4}$ is the mean backscattering coefficient of the free atmosphere above the boundary layer.

The vertical profile of the backscattering coefficient $B(z)$ including three steps is presented as a sum of scaled 
complementary error functions and the backscattered signal from the free atmosphere:

$$
B(z)=\sum_{i=1}^{3} \Delta B_{i j} \operatorname{erfc}\left(\frac{z-H_{i}}{\Delta h_{i}}\right)+B_{4}, \text { where } j=i+1 .
$$

The scaling factor of the layer $i$ is defined as $\Delta B_{i j}=$ $\left(B_{i}-B_{j}\right) / 2$, and $B_{4}$ represents the backscattered background signal. The unknown parameter $\Delta h_{i}$ in the denominator is proportional to $\mathrm{ELT}_{i}$. The parameter $H_{i}$ (location) and $\Delta h_{i}$ (shape) are solved by unconstrained nonlinear optimization. The scaling factors, the backscattered background signal, and the unknown parameters are assumed constant during one averaging time period (15 min). To determine the $\mathrm{MH}$, we require $B_{1}>$ $B_{2}$ and $B_{1}>B_{3}$. This requirement is due to the presumption of gradually decreasing $B_{i}$ with height (Fig. 3). The same requirement does not pertain to $B_{4}$ because this parameter describes the free atmosphere and it may be larger than $B_{1}$ because of clouds above the ABL.

The ceilometer receives the backscattered signal from one height interval at a time. We apply the properties of the complementary error function $[\operatorname{erfc}(\infty)=0, \operatorname{erfc}(0)=$ 1 , and $\operatorname{erfc}(-\infty)=2$ ] to Eq. (3a) separately at points $z=$ $H_{i}, h_{1}$, and $h_{4}$. The corresponding backscattering coefficients in Eq. (3a) reduce to $B\left(H_{i}\right)=\left(B_{i}+B_{i+1}\right) / 2$, $B\left(h_{1}\right)=B_{1}$, and $B\left(h_{4}\right)=B_{4}$. This result is consistent with the above stated requirements for the equation.

This procedure could be easily extended to an $n$-step function [see Eq. (3b)], though analysis of the dataset in this study suggests that one to three layers is enough. Specifically,

$B(z)=\sum_{i=1}^{n} \Delta B_{i j} \operatorname{erfc}\left(\frac{z-H_{i}}{\Delta h_{i}}\right)+B_{n+1}, \quad$ where $j=i+1$

and $B_{n+1}$ is the backscattered signal from the free atmosphere. The unknown parameters $H_{i}$ and $\Delta h_{i}$ are, as earlier, solved by optimization.

The vertical profile of backscattering coefficient is associated with the vertical aerosol density profile. However, the backscattering coefficient determined by a single-wavelength ceilometer is also sensitive to the size distribution of aerosols, which complicates the physical interpretation. Possible changes in the size distribution of the aerosols influence, not only the strength of the backscattered signal, but also, to a minor degree, the heights $H_{i}$.

Thus, the three-step idealized-profile method can distinguish the top of the surface layer from the top of the mixed layer, in principle. The role of the uppermost step in the profile of backscattering coefficient is not yet fully understood from the measurements of the singlewavelength ceilometer. More sophisticated instruments (using several wavelengths) are needed to show whether the uppermost step is an artifact or a real aerosol layer. According to Haeffelin et al. (2011), the layers associated with real aerosol number concentrations and the height $H_{i}$ depend on the wavelength. Overlapping of aerosol layers decreases the sensitivity of the three-step method. This is to be expected in urban environments, where long-range transported aerosols, aged background urban aerosols, and fresh aerosol plumes originating from local urban particulate matter emissions can be commingled.

The fitting procedure is automated with the Matlab R2009a software package (MathWorks, Inc.). The parameters $H_{i}$ and $\Delta h_{i}(i=1,2,3)$ in Eq. (3a) are determined by minimizing the root-mean-square (RMS) deviation between the idealized profile $B(z)$ and the measured profile $b(z)$. Trial runs using these Helsinki Testbed data (2005-07) with the three-step idealizedprofile method show that, if all the parameters are adjustable, then the fitting often fails to follow the shape of the original measured profile as it should. Therefore, the parameters $B_{1}$ (the backscattering coefficient at the lowest measurement level) and $B_{4}$ (the mean backscattering coefficient in the free atmosphere above the boundary layer) in Eq. (3a) are kept fixed during the fitting. In this study, we define $B_{4}$ as the mean backscattering coefficient $2-4 \mathrm{~km}$ above ground, which is thick enough to prevent any effects of occasional peaks in the backscattering coefficient. The levels for defining $B_{4}$ are optimal for Helsinki Testbed data because the unstable MH never reaches very high values, but it may be reasonable to vary this layer by season at lower latitudes where convection is much stronger.

All the other parameters in Eq. (3a) (i.e., $B_{2}, B_{3}, H_{i}$, and $\left.\Delta h_{i}\right)$ are adjustable. The fitting strongly depends upon the initial values of the adjustable parameters because errors in initial values, especially the ones related to steps 1 and 2, can lead to erroneous results. The initial values of $H_{i}(i=1,2,3)$ are selected as the three largest monotonic decreases of the backscattering signal as function of height. The sensitivity of the $\mathrm{MH}$ estimates to the initial values in the optimization may be decreased by using appropriate empirical constraints. Negative $B_{i}$ can occur, but, because the procedure depends on the profile shape and not the absolute backscattering values, this does not affect the MH estimation.

The three-step idealized-profile method produces three estimates for MH. We choose the one connected to the largest decrease of the idealized profile of 
backscattering coefficient to mark the MH. However, one exception applies: the maximum estimate for the MH is set to $2200 \mathrm{~m}$. This exception is based on MH estimates from 296 soundings at Vantaanlaakso (200507) with only one estimated MH exceeding $2000 \mathrm{~m}$. However, the ceilometer often reports a strong gradient at $2500 \mathrm{~m}$, most probably due to the signal weakening at this height. Without this constraint for $\mathrm{MH}$, this artificial gradient could be mistaken for MH if weaker gradients were present closer to the ground. The height constraint for $\mathrm{MH}$ is reasonable under similar climatological conditions to Finland, but a higher value should probably be chosen at lower latitudes where convection is much stronger. Estimating very low $\mathrm{MH}$ under very strong stable conditions carries some uncertainty, as well, because the lowest measuring level for the ceilometer is $10 \mathrm{~m}$ (which enables estimating a minimum $\mathrm{MH}$ of $20 \mathrm{~m}$ ), whereas the lowest level for radiosoundings is $40 \mathrm{~m}$.

Although the CL31 ceilometer has a range up to $7500 \mathrm{~m}$ (Table 1), white noise from altitudes above $4000 \mathrm{~m}$ can lead to an imperfect fit to $B$. Consequently, in this study, we eliminate data above $4000 \mathrm{~m}$, an altitude that exceeds the maximum observed MH in Finland yet still provides some information on the free atmosphere.

\section{3) THE BASIC GRAdIENT METHOdS}

In addition to the idealized-profile method, we also study some simpler gradient methods to estimate the $\mathrm{MH}$ from the measured backscattering coefficient profile. The strength of the gradient method is its simplicity-the gradient is mathematically easy to find. But, it is also possible to pick a wrong gradient. The main difference between the idealized-profile method and basic gradient method is the different interpretation of gradients. The gradient for an idealized profile (cumulative distribution) represents the signal normal density distribution, whereas the gradient for the basic gradient method leaves open the type of the distribution. Although the three-step method only fits profiles, the basic gradient method requires both fitting and computing gradients (e.g., Strang 2007, p. 448). Therefore, the three-step method is expected to yield smaller errors than the basic gradient method, especially for noisy data. We use three different methods to find the gradient associated with the MH:

1) maximum of the negative gradient of the backscattering coefficient profile ( $\left.h_{\text {grad,max }}\right)$,

2) first negative gradient exceeding the threshold value of $-2 \overline{\partial b / \partial z_{i}}\left(h_{\text {grad,first }}\right)$, and

3) the start of the longest monotonous negative gradient ( $\left.h_{\text {grad,long }}\right)$.
Besides finding these gradients from the initially averaged data (15-min time average, 90-m moving height average), we also test the effect of a second smoothing with a 90-m moving-average filter.

\section{4) The STANDARD DEVIATION METHOD FOR MH ESTIMATION}

We also want to examine some less commonly used methods for MH estimation, such as methods based on the STD profiles. The aim is to study if the STD approach is more suitable for the $\mathrm{MH}$ evaluation than the three-step idealized-profile method, and, more importantly, its suitability as a performance metric for assessing the quality of the MH estimates by the three-step idealized-profile method.

We calculate the standard deviation both over vertical $\left(\mathrm{STD}_{v}\right)$ and time $\left(\mathrm{STD}_{t}\right)$ axes. Like the gradient methods, the $\mathrm{STD}_{v}$ method requires a gradient between the $\mathrm{ABL}$ and the free atmosphere, whereas the $\mathrm{STD}_{t}$ method requires temporal fluctuation at the top of the ABL. STD is calculated from individual 1-min profiles over $15 \mathrm{~min}$, whereas $\mathrm{STD}_{v}$ is calculated over 100 -m moving-average blocks starting at a height of $50 \mathrm{~m}$. Both standard deviation profiles $\left(\mathrm{STD}_{v}\right.$ and $\left.\mathrm{STD}_{t}\right)$ search for maxima as the indicator of MH. The first peak exceeding $150 \%$ of the average STD in the layer $0-500 \mathrm{~m}$ is chosen to be $\mathrm{MH}$. These estimates for the $\mathrm{MH}\left(\mathrm{MH}_{\mathrm{STD} v} ; \mathrm{MH}_{\mathrm{STD} t}\right)$ are compared with MHs evaluated by radiosoundings (assumed to be the reference $\mathrm{MH}$ ) and also to MHs evaluated by the three-step method for assessing if the STD approach could provide additional confidence metrics for the $\mathrm{MH}$ evaluated by ceilometer.

\section{Results and discussion}

In this section, we first discuss the different backscattering coefficient profile types measured by the CL31 ceilometer and the justification for the three steps (section 4a). The sensitivity for the initial values is discussed in section 4b. Comparing MHs determined by ceilometer (the one-step and three-step idealized-profile methods, basic gradient methods, and the STD method) and MHs determined by radiosoundings is discussed in sections $4 \mathrm{c}$ and $4 \mathrm{~d}$.

The number of observations in this study is constrained by the number of available radiosoundings $(N=245)$. Since the ceilometer is incapable of detecting the $\mathrm{MH}$ in the presence of low-level clouds or rain, 132 cloudyrainy situations are removed from the original dataset. Another 16 situations are removed because they possess low backscattering coefficient values near the surface, such that $B_{2}$ or $B_{3}$ are larger or equal to $B_{1}$. For the 16 rejected profiles, the average values are $B_{1 \text {, mean }}=408$ 

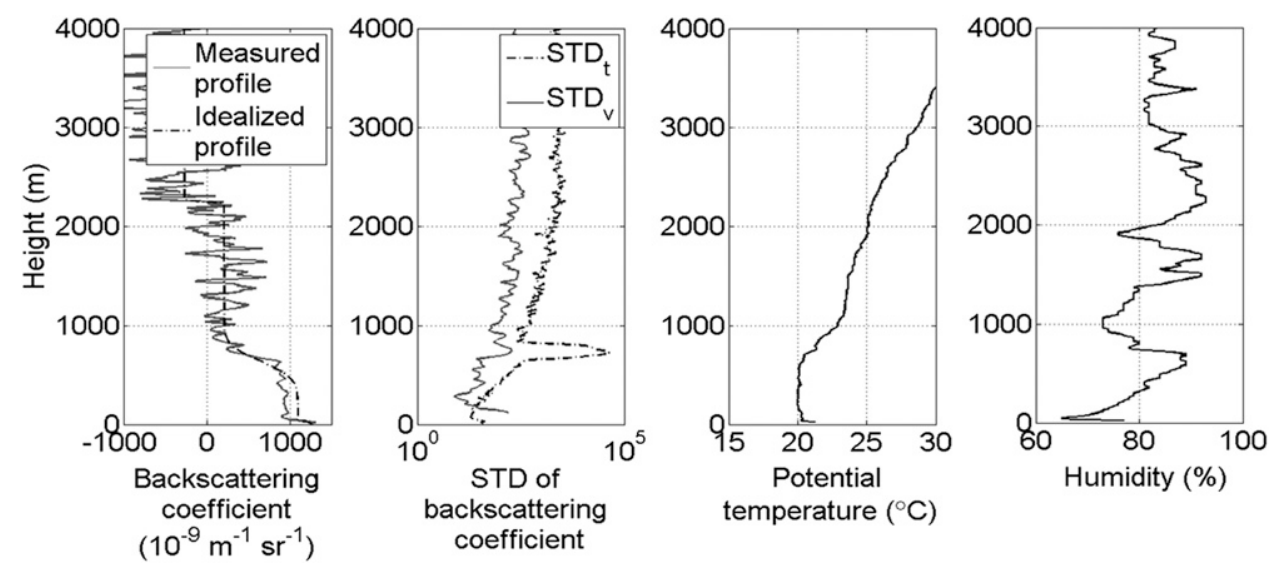

FIG. 4. Example of a fitted profile following the three-step idealized-profile shape with a concomitant temperature and humidity radiosounding (Vantaanlaakso, 1050 UTC 22 Aug 2006). The MH evaluated from the ceilometer profile by the three-step method is $680 \mathrm{~m}\left(H_{1}=30 \mathrm{~m} ; H_{2}=680 \mathrm{~m} ; H_{3}=2130 \mathrm{~m}\right)$, $690 \mathrm{~m}$ by the $\mathrm{STD}_{v}$ method, and $720 \mathrm{~m}$ by the $\mathrm{STD}_{t}$ method, whereas the MH evaluated from the radiosounding is $720 \mathrm{~m}$.

and $B_{1 \text {,median }}=368$, whereas, for the remaining 97 profiles, the average values are $B_{1 \text {,mean }}=4074$ and $B_{1 \text {,median }}=903$. This latter big difference is due to a few (7) very large $B_{1}$ values $(>10000)$, which occur under situations with fog or mist or situations that possess a surface inversion. When such extremely large backscattering values occur at the lowest measurement levels, the backscattered signal does not penetrate into higher measurement levels, yielding an artificial weakening of the backscattered signal and an artificial gradient in the backscattered signal profile. Thus, the final number of observations is 97 , which serve as the basis for the analysis presented in the rest of this section.

\section{a. Evaluation of backscattering coefficient profiles}

The measured ceilometer backscattering coefficient profiles include four types of profile shapes. About half (56\%; the percentages that follow correspond roughly to the number of actual cases) of the measured backscattering coefficient profiles follow the theoretical profile shape with three distinct steps (Fig. 4). In contrast, 31\% of the measured backscattering coefficient profiles have only two steps with steps $1\left(H_{1}\right)$ and $2\left(H_{2}\right)$ blended together (upper row of Fig. 5). In $3 \%$ of the measured profiles, all the steps are blended into one creating a single step (lower row of Fig. 5). Finally, $10 \%$ of the observations display a residual layer or the remnants of a previous cloud above the ABL.

The distribution of steps determining the $\mathrm{MH}$ is presented in Table 3. Most of the MH estimates are based on $\mathrm{H}_{2}$ ( $82 \%$ of the observations). In contrast, $H_{1}$ determines the $\mathrm{MH}$ in $10 \%$ of the cases. Finally, $\mathrm{H}_{3}$ determines the $\mathrm{MH}$ in $7 \%$ of the cases, typically when the
$\mathrm{MH}$ is quite weak, the $\mathrm{MH}$ lies above the threshold of $2200 \mathrm{~m}$, or both.

The physical explanation for the lowest layer (in the case of three steps in the measured backscattering coefficient profile) varies with the stability conditions. In convective, near-neutral, and stable conditions, $H_{1}$ is the surface layer, whereas, in very stable conditions, the surface layer is absent and $H_{1}$ is used as the MH. Alternatively, in these very stable conditions, $H_{1}$ forms one large step together with $H_{2}$ (and possibly also with $H_{3}$ ).

The middle layer $\mathrm{H}_{2}$ in the case of three steps is the mixing layer. If $H_{1}$ is used as the mixing layer, then $H_{2}$ defines the height of the residual layer. The uppermost step, $H_{3}$, is used as an extra step. In a few cases, $H_{3}$ is used as the $\mathrm{MH}$ (in these cases, $\mathrm{H}_{2}$ is associated with a minor gradient within the mixed layer), but mostly $\mathrm{H}_{3}$ is associated with the gradient caused by the weakened signal. However, a generally valid physical explanation for $H_{3}$ cannot be given, as a more sophisticated instrument (using several wavelengths and also measuring the wind profile) is needed to show whether the step is an artifact or a real aerosol layer.

\section{b. Sensitivity for initial values-Case study}

The initial values $H_{i, 0}$ in the optimization procedure for estimating the MH play an important role. The easiest option is to use a fixed value for $H_{i, 0}$. However, based on the data available, this option is not advisable because initial values that are too high or too low lead to a failure in identification of the steps. A demonstration of such a case is shown in Fig. 6 (1028 UTC 13 August 2006). In this case, the fitting algorithm suggests the following initial values: $H_{1,0}=60 \mathrm{~m}, H_{2,0}=690 \mathrm{~m}$, 

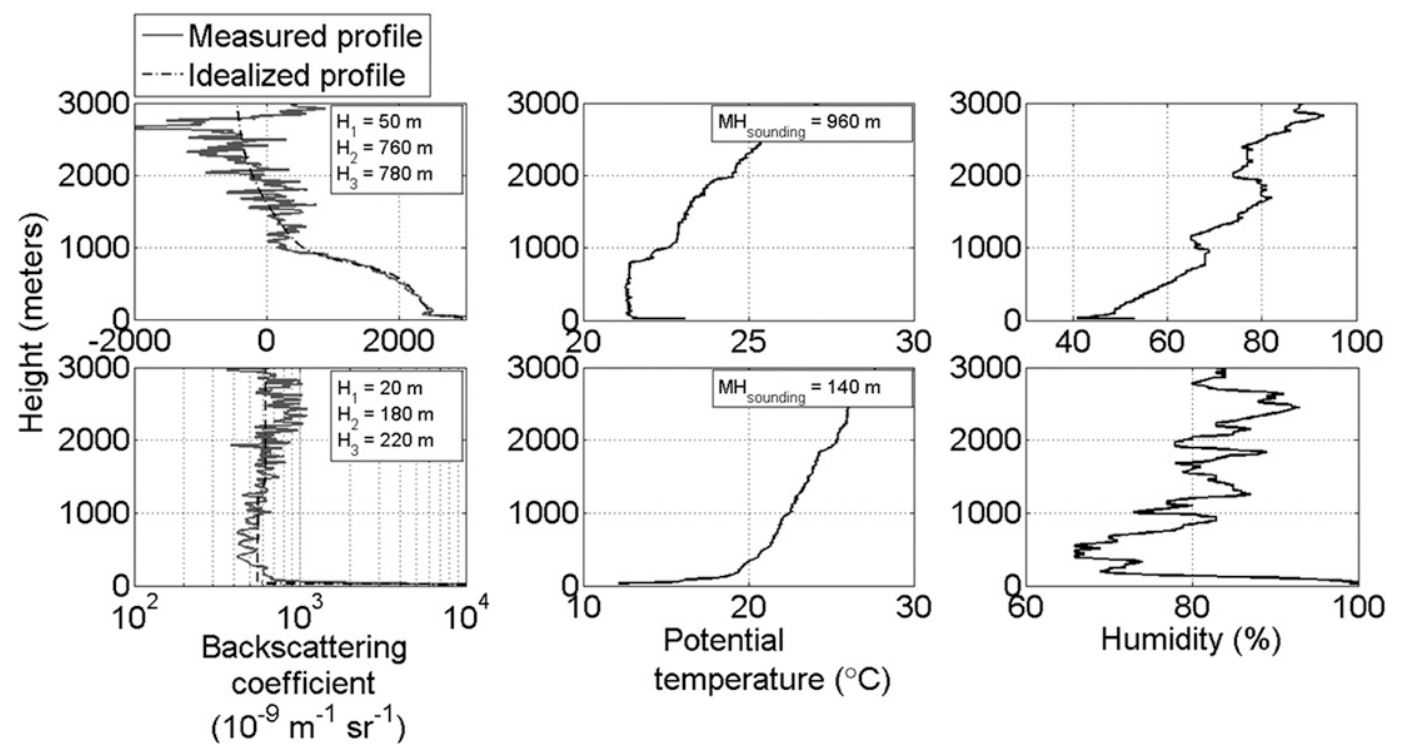

FIG. 5. Two examples of ideal backscattering coefficient profile shapes with concomitant temperature and humidity radiosoundings. (top ) Vantaanlaakso, 1028 UTC 9 Aug 2006, steps 2 and 3 are merged into one step with $H_{2}$ used as the MH. (bottom) Vantaanlaakso, 0228 UTC 21 Aug 2006, all three steps are merged into one step with $H_{3}$ used as the MH.

$H_{3,0}=2250 \mathrm{~m}$ [referred to as the initial value set 2 $\left.\left(\mathrm{IVS}_{2}\right)\right]$. We also explore the effect of initial values that are lower than suggested $\left[H_{1,0}=10 \mathrm{~m}, H_{2,0}=H_{3,0}=\right.$ $100 \mathrm{~m}$; initial value set $\left.1\left(\mathrm{IVS}_{1}\right)\right]$ and higher than suggested $\left[H_{1,0}=H_{2,0}=2000 \mathrm{~m}, H_{3,0}=3000 \mathrm{~m}\right.$; initial value set $\left.3\left(\mathrm{IVS}_{3}\right)\right]$. Using initial value sets $\mathrm{IVS}_{1}$ and $\mathrm{IVS}_{2}$ leads to correct identification of all the steps. Even though $\mathrm{IVS}_{1}$ leads to a numerically correct result, the fitted idealized profile does not follow the shape of the measured profile (Fig. 6). Finally, the use of higher initial values than suggested by $\mathrm{IVS}_{3}$ leads to a failed fitting. The fitting algorithm recognizes the lowest step $\left(H_{1}\right)$, but does not recognize the second step $\mathrm{H}_{2}$ found by using the two other sets of initial values.

\section{c. Comparison of MHs evaluated by ceilometer and radiosoundings}

The comparison of MHs evaluated by ceilometer and radiosounding is displayed in Fig. 7 for the 97 selected cases. These cases are noncloudy with relatively strong backscattering coefficient near the surface: $B_{1}$ is always the largest of the $B_{i} ; i=1,2,3$. A regression line is fitted to the 97 cases, yielding

$$
\mathrm{MH}_{\text {ceilometer }}=(0.90 \pm 0.08) \mathrm{MH}_{\text {sounding }}+(49 \pm 44) .
$$

The error margins of Eq. (4) correspond to the $95 \%$ confidence level of the regression coefficients. The correlation between $\mathrm{MHs}$ evaluated from the ceilometer and radiosounding observations is significant (correlation coefficient $r=0.91$; correlation's $t$ score by Student's $t$ test $t=17.2$; confidence level $p<0.001$ ). On average, the MHs estimated with the ceilometer are slightly higher than the MHs estimated from radiosoundings. Despite differences in the methods, the MHs extracted from the ceilometer signal agree fairly well on average with the MHs determined by sounding. However, this is true only for the situations with a distinct difference between the layer adjacent to the ground (i.e., the $\mathrm{MH}$ ) and the free atmosphere.

TABLE 3. Distribution of steps determining the MH according to stability (determined from the Richardson number calculated in the layer $28-100 \mathrm{~m}$ above the ground).

\begin{tabular}{lccccc}
\hline \hline & & Near-neutral & & \\
& Unstable Ri $<0$ & $0 \leq \mathrm{Ri}<1$ & Stable $1 \leq \mathrm{Ri}<10$ & Very stable Ri $\geq 10$ & Tot no. of cases \\
\hline$H_{1}$ & 0 & 3 & 5 & 2 & 10 \\
$H_{2}$ & 10 & 22 & 41 & 0 & 80 \\
$H_{3}$ & 5 & 0 & 2 & 9 & 97 \\
Tot no. of cases & 15 & 25 & 48 & 9 & 97 \\
\hline
\end{tabular}



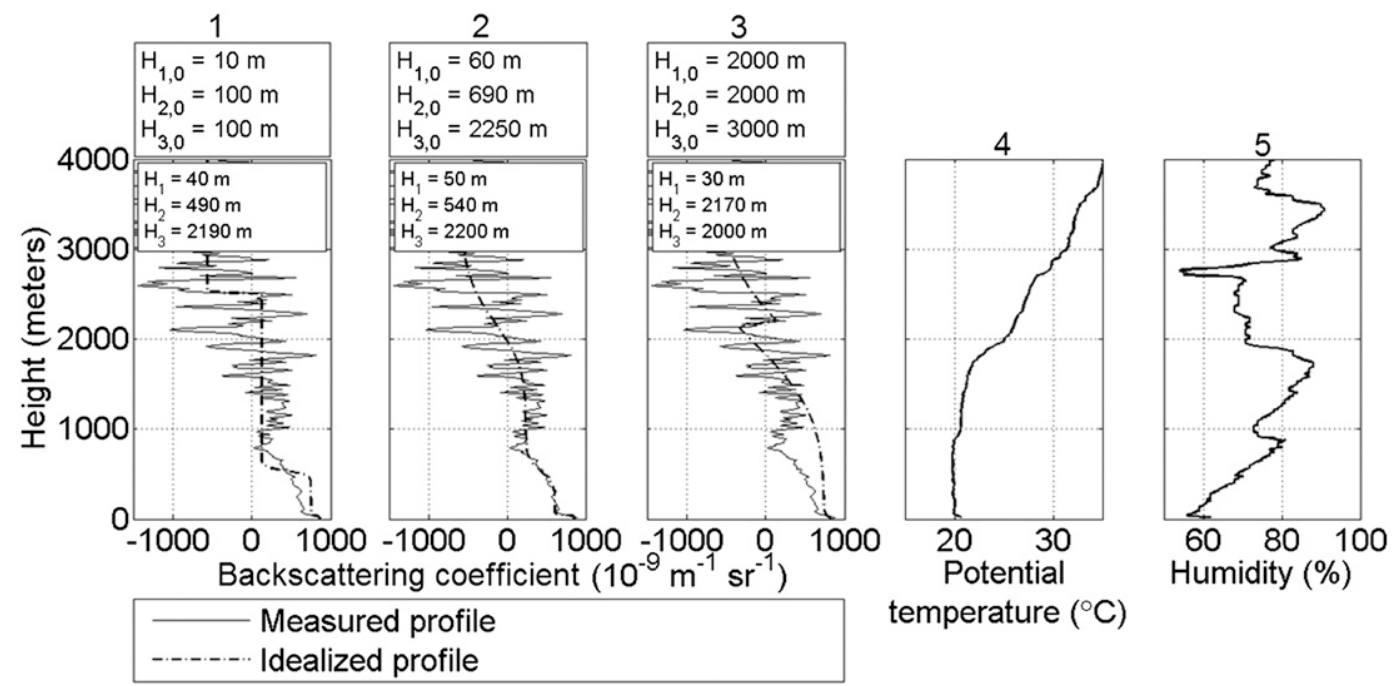

temperature $\left({ }^{\circ} \mathrm{C}\right)$

FIG. 6. Examples of the effect of initial values on the MH estimation. 1) The initial value set is lower than suggested by the fitting algorithm. 2) The initial value set as suggested by the fitting algorithm is used. 3) The initial value set is higher than suggested by the fitting algorithm. The simultaneous radiosounding at Vantaanlaakso at 1028 UTC 13 Aug 2006 is shown 4) for potential temperature and 5) for humidity.

A more careful examination is carried out for the 25 cases displaying large relative differences between the two estimates-outside the domain $-0.5<$ $\left[\left(\mathrm{MH}_{\text {ceilometer }}-\mathrm{MH}_{\text {sounding }}\right) / \mathrm{MH}_{\text {sounding }}\right]<1$. In $15(60 \%)$ of these 25 cases with a large relative difference, the ceilometer method overestimates the $\mathrm{MH}$ compared to the radiosounding - that is, $\left[\left(\mathrm{MH}_{\text {ceilometer }}-\mathrm{MH}_{\text {sounding }}\right) /\right.$ $\left.\mathrm{MH}_{\text {sounding }}\right]>1$. In $6(40 \%)$ of these 15 overestimation cases, the ceilometer indicates the layer of continuous strong backscattering coefficient (i.e., the boundary layer) extending higher than could be expected on the basis of the temperature and Ri profiles. The 9 of the 15 observations $(60 \%$ of the overestimation cases) are characterized either by a residual layer or remnants of a previous cloud near the surface (Fig. 8).

In $10(40 \%)$ of the 25 cases displaying a large relative difference, the ceilometer indicates lower MH than could be calculated from the radiosounding profile$\left[\left(\mathrm{MH}_{\text {ceilometer }}-\mathrm{MH}_{\text {sounding }}\right) / \mathrm{MH}_{\text {sounding }}\right]<0.5$. In $8(80 \%)$ of these 10 cases, a cloud or a residual layer could be observed above the ground-based aerosol layer. However, the other $2(20 \%)$ of the 10 underestimation cases show no physical explanation for the large difference between MHs evaluated from the radiosoundings and the three-step idealized-profile method from the ceilometer. In these cases, the observed backscattering coefficient profile shows a shallower aerosol layer than could be expected.

Most of the observations with large relative differences between MHs from the ceilometer and the radiosounding are characterized by stable conditions. Only one observation, with $\mathrm{MH}_{\text {ceilometer }}$ relatively much lower than $\mathrm{MH}_{\text {sounding, }}$, is recorded in unstable conditions $(\mathrm{Ri}=$ $-0.18)$. However, the skewness of the stability distribution is probably because the $\mathrm{MH}$ is generally lower in stable than in unstable situations. Thus, even a $100-\mathrm{m}$ difference between $\mathrm{MH}_{\text {ceilometer }}$ and $\mathrm{MH}_{\text {sounding }}$ can lead

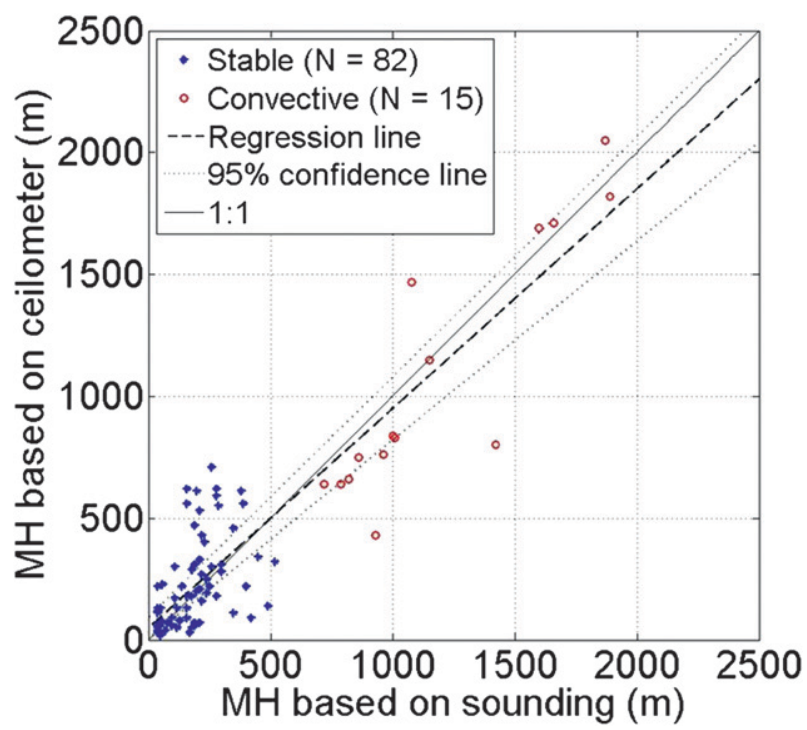

FIG. 7. Comparison between mixing heights determined from the radiosoundings and the three-step idealized-profile method from the ceilometer data in the Helsinki metropolitan area from 2 Jan 2006 to 13 Mar 2007. The blue symbols represent the MHs determined during stable situations, and the red circles represent the MHs determined during convective situations. 


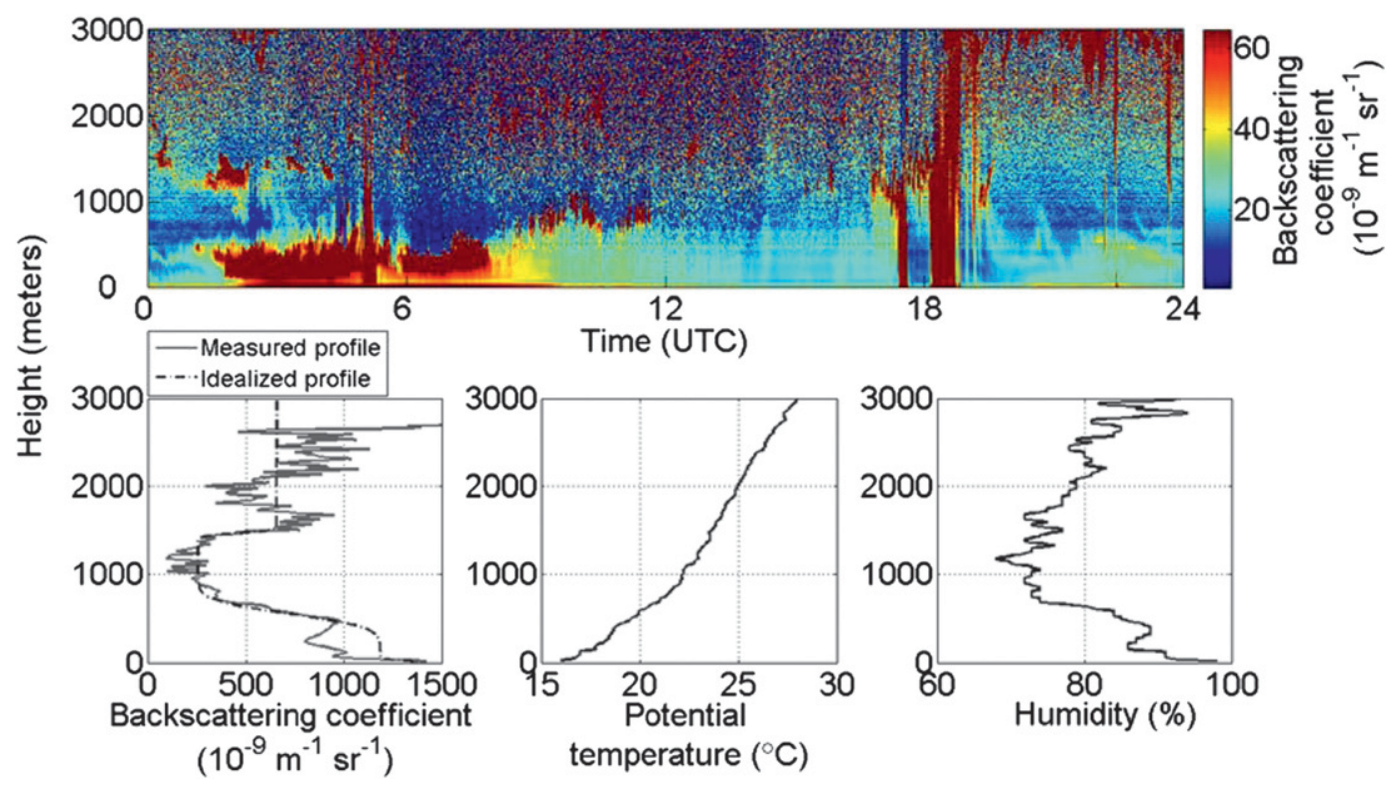

FIG. 8. Example of a large relative difference between the MH determined from the three-step idealized-profile method using ceilometer data $(560 \mathrm{~m})$ and the $\mathrm{MH}$ determined from radiosounding $(390 \mathrm{~m})$ : Vantaanlaakso at

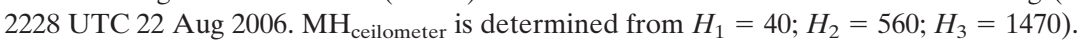

to a relative difference of $250 \%$ when discussing very low MHs.

The histogram of MHs derived from soundings and ceilometer observations is shown in Fig. 9. A substantial fraction of shallow mixing layers due to the bias in observation times is apparent, with $85 \%$ of the observations collected either during night or in winter when the $\mathrm{MH}$ is low. These results do not represent the actual climatological distribution of MHs in southern Finland. On the other hand, because major pollution episodes occur with low MHs under stable conditions, our dataset, with its good coverage of the spectrum of stable conditions, is of practical relevance.

In most categories in Fig. 9, the number of cases is similar for MHs estimated by soundings and the ceilometer.
However, the group "500-749 m" shows a distinct peak in MHs derived from the ceilometer. This is partly due to the large relative difference cases (discussed above), where remnants of previous cloud or a residual layer are situated above the ground-based aerosol layer.

We also compare MHs estimated by this three-step idealized-profile method with the one-step idealized-profile method. The original one-step idealized-profile method is capable of detecting the $\mathrm{MH}$ when the ground-based aerosol layer is strong (i.e., only one step present in the measured backscattering coefficient profile), but in most cases the original one-step method was confused by more than one step in the measured backscattering coefficient profile. Thus, the correlation

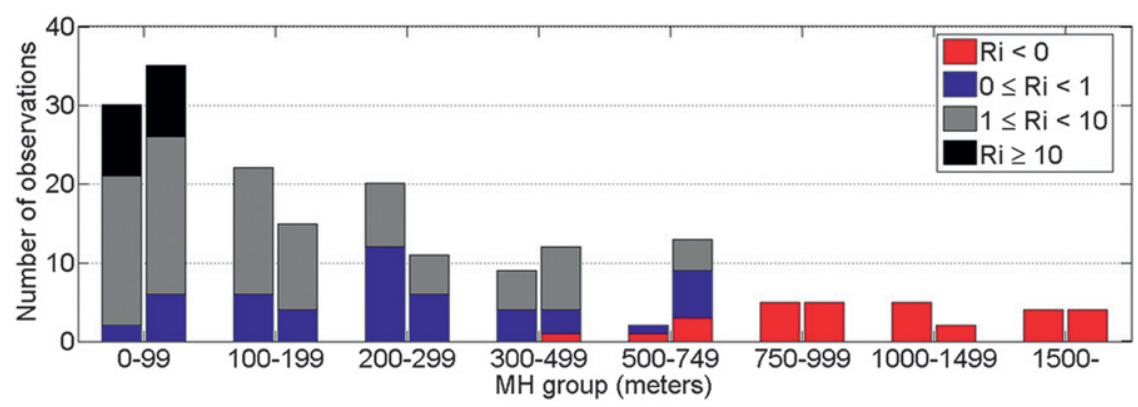

FIG. 9. Histogram of MHs derived from radiosoundings (left bar of each pair) and the threestep idealized-profile method from ceilometer data (right bar) in the Helsinki metropolitan area between 2 Jan 2006 and 13 Mar 2007, segregated by Ri. 


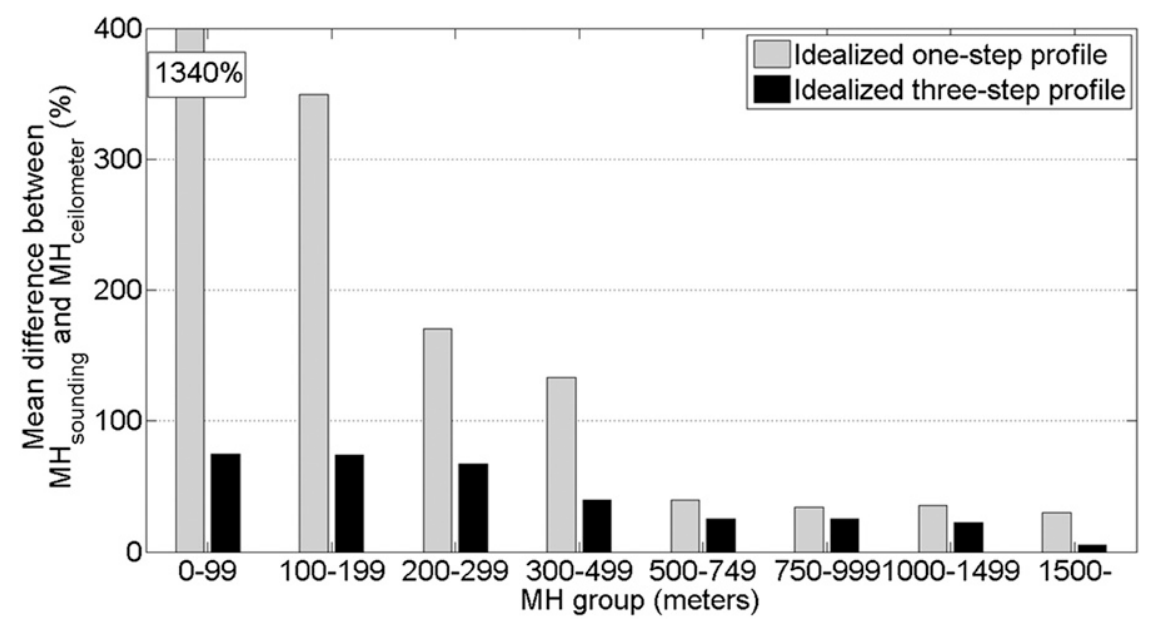

FIG. 10. Comparison of the mean relative difference between MHs evaluated from ceilometer data and radiosounding observations in the Helsinki metropolitan area between 2 Jan 2006 and 13 Mar 2007 for the one-step idealized-profile method (gray) and the three-step idealizedprofile method (black).

between MHs evaluated from the ceilometer and radiosounding observations is weak $(r=0.28)$.

The comparison between Deviation $_{1 \text { step }}=$ $\left(\left|\mathrm{MH}_{\text {ceilometer,1step }}-\mathrm{MH}_{\text {sounding }}\right|\right) / \mathrm{MH}_{\text {sounding }} \quad$ and Deviation $_{3 \text { step }}=\left(\left|\mathrm{MH}_{\text {ceilometer,3step }}-\mathrm{MH}_{\text {sounding }}\right|\right) /$ $\mathrm{MH}_{\text {sounding }}$ is presented in Fig. 10. In most of the cases, the one-step idealized-profile method failed to detect the MH properly. The presence of multiple layers confuses the one-step method. The one-step method blends all the layers in one thick layer, whereas the three-step method is able to identify the strongest layers, providing an improved determination of the $\mathrm{MH}$.

\section{d. Comparison between MHs evaluated by gradient methods, STD method, and radiosoundings}

We compare three gradient methods (the maximum of the negative gradient, the first gradient exceeding the mean negative gradient, and the beginning of the longest continuous gradient) with the $\mathrm{MH}$ from the radiosounding data. These three gradients are found from the same data (hereinafter called the normal dataset) as used in the three-step profile method, but also from data averaged a second time (90-m moving-average along the height axis) (hereafter called the double-averaged dataset).

In both datasets, the height of the maximum negative gradient $\left(h_{\text {grad,max }}\right)$ is mostly associated with the strong gradient peaks caused by noise $(82 \%$ of the cases in the normal dataset; $67 \%$ of the cases with double-averaged dataset), whereas the minority of $h_{\text {grad,max }}$ is associated with the surface layer (18\% of the normal dataset; $29 \%$ of the double-averaged dataset). In $4 \%$ of the doubleaveraged dataset, $h_{\text {grad,max }}$ is found between the surface layer and noisy layer. In these cases, $h_{\text {grad,max }}$ coincides with the MH evaluated by the three-step method and radiosoundings.

In the normal dataset, the first large negative gradient, $h_{\text {grad,first }}$ (i.e., $\partial b / \partial z<-2 \overline{\partial b / \partial z}$ ), is always found below $100 \mathrm{~m}$ AGL. In the double-averaged dataset, however, this is true in only $85 \%$ of the cases. In $7 \%$ of the doubleaveraged dataset cases, $h_{\text {grad,first }}$ is near the $\mathrm{MH}$ evaluated by ceilometer. In the remaining $8 \%, h_{\text {grad,first }}$ is between $100 \mathrm{~m} \mathrm{AGL}$ and $\mathrm{MH}_{\text {ceilometer. }}$.

The beginning of the longest continuous gradient proves to be the best approximation for the $\mathrm{MH}_{\text {ceilometer }}$, especially in the double-averaged dataset. The mean difference between $h_{\text {grad,long }}$ and $\mathrm{MH}_{\text {ceilometer }}$ is $180 \mathrm{~m}$ in the double-averaged dataset, whereas the mean difference between $h_{\text {grad,long }}$ and $\mathrm{MH}_{\text {ceilometer }}$ is $380 \mathrm{~m}$ in the normal dataset. The correlation coefficients and regression lines between $h_{\text {grad,max }}, h_{\text {grad,first }}, h_{\text {grad,long, }}$, and MHs evaluated by radiosoundings are presented in Table 4 .

However, the suitability of the gradient methods cannot be judged by this dataset as we had only a very brief look at the possibilities of the gradient methods. A more detailed study on the gradient method (Sicard et al. 2006; Haeffelin et al. 2011) shows the gradient and also the wavelet method to be suitable for $\mathrm{MH}$ evaluation. The correlation coefficient between MHs evaluated by ceilometer and the reference radiosounding method in those studies is as high as 0.96 .

The standard deviation profile is calculated over the time $\left(\mathrm{STD}_{t}\right)$ and vertical $\left(\mathrm{STD}_{v}\right)$ axes. We use the first peak in each profile as the $\mathrm{MH}$; neither one provides enough information for the $\mathrm{MH}$ evaluation solely. For the $\mathrm{STD}_{t}$ method, the main restriction is the lack of distinct peaks (in $21 \%$ of the observations, $\mathrm{STD}_{t}$ increases 
TABLE 4. The correlation coefficients and regression lines between $h_{\text {grad,max }}, h_{\text {grad,first }}, h_{\text {grad, long }}$ and MHs evaluated by radiosoundings.

\begin{tabular}{llll}
\hline \hline & & $\begin{array}{c}\text { Correlation } \\
\text { coef }\end{array}$ & \multicolumn{1}{c}{ Regression line } \\
\hline Simple averaging & Max negative gradient & 0.16 & $\mathrm{MH}_{\text {sounding }}=(0.53 \pm 0.64) h_{\text {grad,max }}+(2500 \pm 340)$ \\
& First strong gradient & 0.19 & $\mathrm{MH}_{\text {sounding }}=-(4.2 \pm 4.4) \times 10^{-3} h_{\text {grad,first }}+(36 \pm 2)$ \\
& Beginning of the longest gradient & 0.19 & $\mathrm{MH}_{\text {sounding }}=(0.25 \pm 0.26) h_{\text {grad,long }}+(320 \pm 140)$ \\
Double averaging & Max negative gradient & 0.37 & $\mathrm{MH}_{\text {sounding }}=(1.3 \pm 0.68) h_{\text {grad,max }}+(1700 \pm 360)$ \\
& First strong gradient & 0.19 & $\mathrm{MH}_{\text {sounding }}=(47 \pm 48) \times 10^{-3} h_{\text {grad,first }}+(88 \pm 25)$ \\
& Beginning of the longest gradient & 0.77 & $\mathrm{MH}_{\text {sounding }}=(0.64 \pm 0.11) h_{\text {grad,long }}+(29 \pm 56)$ \\
\hline
\end{tabular}

monotonically with no sharp peaks in the profile-this problem is mostly observed in convective cases with high $\mathrm{MH})$. In contrast, the $\mathrm{STD}_{v}$ approach always reports the first peak below $1200 \mathrm{~m}$ (thus making it impossible to identify any peak in $\mathrm{STD}_{v}$ connected to high $\mathrm{MH})$ due to the increase in noise. Also, because of the computational procedure for $\mathrm{STD}_{v}$ the lowest possible peak is found at $60 \mathrm{~m}$.

The correlation between MHs evaluated by the $\mathrm{STD}_{t}$ method and radiosounding observations is moderate ( $r=0.6$; number of observations $N=77)$, whereas the correlation between MHs evaluated by the $\mathrm{STD}_{v}$ method and radiosounding observations is weak $(r=$ 0.35 ; number of observations $N=97$ ).

The comparison between the MHs evaluated by peaks in STD profiles and soundings is displayed in Fig. 11. A regression line is fitted to the observations, yielding

$$
\mathrm{MH}_{\mathrm{STD}_{t}}=(0.72 \pm 0.18) \mathrm{MH}_{\text {sounding }}+(140 \pm 77)
$$

and

$$
\mathrm{MH}_{\mathrm{STD}_{v}}=(0.22 \pm 0.12) \mathrm{MH}_{\text {sounding }}+(280 \pm 61)
$$

The error margins of Eqs. (5a) and (5b) correspond to the $95 \%$ confidence level of the regression coefficients.

Despite the shortcomings of the STD method, we find the standard deviation profiles to be useful for the classification of MHs evaluated by the three-step idealized-profile method. The evaluated $\mathrm{MHs}$ are divided into four classes according to the $\mathrm{STD}_{t}$ and the $\mathrm{STD}_{v}$ peaks (Table 5; Fig. 12). The " $\mathrm{MH}_{\text {ceilometer }}$ too high" is especially useful as it identifies most of the overestimation cases.

\section{Conclusions}

In comparison with the original one-step idealizedprofile method, the three-step method has the advantage of taking three aerosol layers into account and thus better copes with real-world situations. Three steps are especially useful when the surface layer is present or a residual layer lies above the boundary layer. As Eresmaa et al. (2006) find, these phenomena complicate the

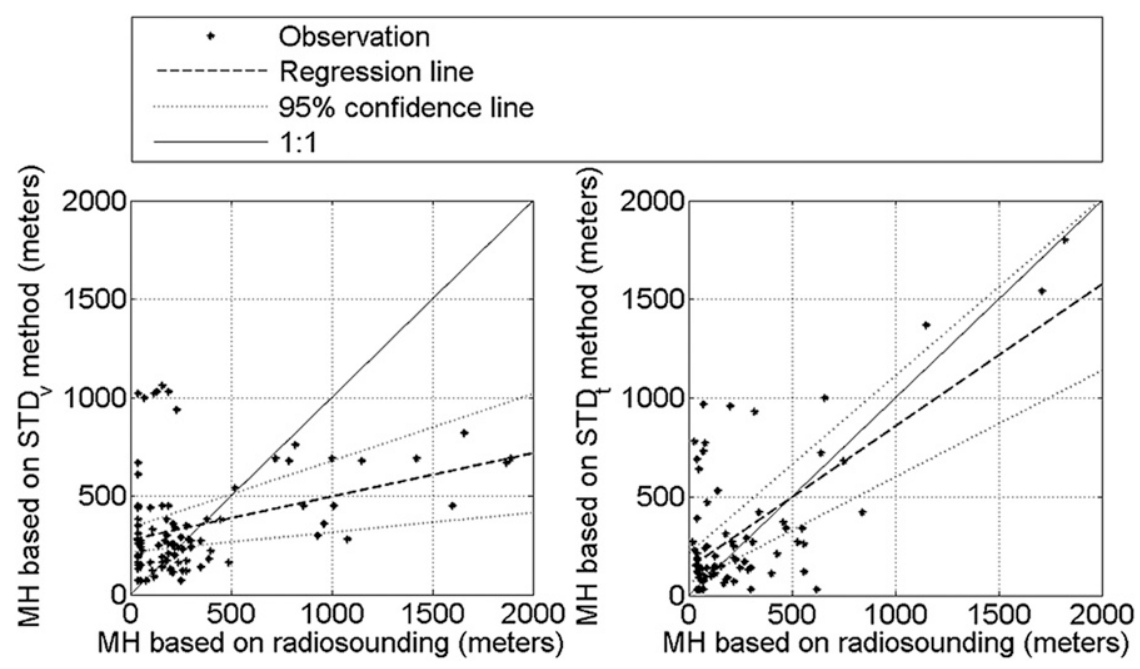

FIG. 11. Comparison between MHs determined from the radiosoundings and the (left) STD and (right) $\mathrm{STD}_{v}$ profile method from the ceilometer data in the Helsinki metropolitan area between 2 Jan 2006 and 13 Mar 2007. 
TABLE 5. The classification of MHs based on STD profiles.

\begin{tabular}{|c|c|c|c|}
\hline & & Regression line & $\begin{array}{l}\text { Correlation } \\
\text { coef }\end{array}$ \\
\hline "Good fit" & $-0.25<\frac{\mathrm{MH}_{\text {ceilometer }}-\mathrm{STD}_{t, v}}{\mathrm{STD}_{t, v}}<0.25$ & $\mathrm{MH}_{\text {sounding }}=0.81 \mathrm{MH}_{\text {ceilometer }}+320$ & 0.95 \\
\hline "Fair fit" & $\begin{array}{r}-0.5 \leq \frac{\mathrm{MH}_{\text {ceilometer }}-\mathrm{STD}_{t, v}}{\mathrm{STD}_{t, v}} \leq-0.25 \\
\text { or } 0.25 \leq \frac{\mathrm{MH}_{\text {ceilometer }}-\mathrm{STD}_{t, v}}{\mathrm{STD}_{t, v}} \leq 0.5\end{array}$ & $\mathrm{MH}_{\text {sounding }}=0.96 \mathrm{MH}_{\text {ceilometer }}+15$ & 0.94 \\
\hline "MH $\mathrm{Meilometer}$ too high" & $\frac{\mathrm{MH}_{\text {ceilometer }}-\mathrm{STD}_{t, v}}{\mathrm{STD}_{t, v}}>0.5$ & $\mathrm{MH}_{\text {sounding }}=0.20 \mathrm{MH}_{\text {ceilometer }}+500$ & 0.12 \\
\hline
\end{tabular}

detection of MH by the one-step method. The three-step method maintains the same advantage as the one-step method because it exploits the whole backscattering coefficient profile, feeling little effect on the fitting from the white noise.

However, the three-step idealized-profile method has two potential limitations.

1) Backscattering coefficient profiles are usable only if aerosols are sufficiently present in the boundary layer [i.e., the backscattering coefficient near the ground $\left(B_{1}\right)$ exceeds $B_{2}$ and $B_{3}$ in the idealized profile], and

2) the semiautomatic numerical solution of the fitting may result in inaccurate values of $\mathrm{MH}$ if not crosschecked against other data, especially in the presence of cloud layers, fog, or remnants of mixed layers.

The three-step idealized-profile method was tested with 97 observations measured in the Helsinki Testbed area, southern Finland, from 2 January 2006 to 13 March 2007. The MHs evaluated with the three-step idealized-profile method had a high correlation $(r=0.91)$ with MHs determined from radiosoundings.

Two simpler methods also were examined: the basic gradient method and the STD method. We tested three criteria for $\mathrm{MH}$ estimation by the basic gradient method: the maximum of the negative gradient, the first gradient exceeding the mean negative gradient, and the beginning of the longest continuous gradient. These criteria were tested with the same data as the three-step idealized-profile method and also with double-averaged data. The maximum of the negative gradient and the first negative gradient exceeding the preset threshold value were associated either with white noise above the $\mathrm{MH}$ or with the surface layer. Also, the beginning of the longest continuous gradient provided no reliable information on $\mathrm{MH}$ as compared to the $\mathrm{MH}$ from the radiosounding. However, the beginning of the longest continuous gradient proved to be the best approximation for the $\mathrm{MH}$ in the double-averaged dataset, with a correlation coefficient of 0.77 with the $\mathrm{MH}$ from the radiosounding.

We also tested the STD method. The STD profile was calculated over the vertical $\left(\mathrm{STD}_{v}\right)$ and time $\left(\mathrm{STD}_{t}\right)$ axis, and both the STD profiles were searched for peaks as an indicator for the $\mathrm{MH}$. Neither of the STD profiles

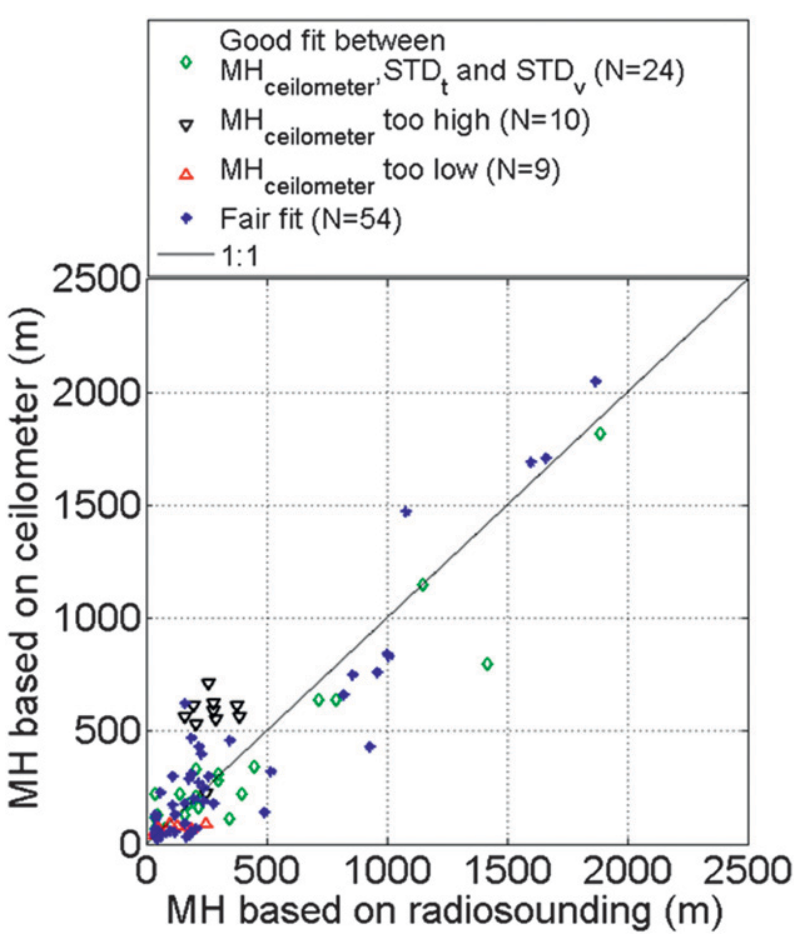

FIG. 12. Comparison between MHs evaluated from the radiosoundings and the three-step idealized-profile method from the ceilometer data in the Helsinki metropolitan area between 2 Jan 2006 and 13 Mar 2007. The green diamonds represent situations with a distinct peak in $\mathrm{STD}_{t}$ and $\mathrm{STD}_{v}$ near the evaluated $\mathrm{MH}_{\text {ceilometer }}$; the downward-pointing black triangles represents situations with a distinct peak in both the $\mathrm{STD}_{t}$ and the $\mathrm{STD}_{v}$ profiles lower than the evaluated $\mathrm{MH}_{\text {ceilometer }}$; and the upward-pointing red triangles represent the situations with a distinct peak in both the $\mathrm{STD}_{t}$ and the $\mathrm{STD}_{v}$ profiles higher than evaluated $\mathrm{MH}_{\text {ceilometer. The blue symbols }}$ represent situations that do not fit in the other three classes. 
was able to evaluate the $\mathrm{MH}$ as compared with $\mathrm{MH}_{\text {sounding. }}$. However, the STD method provided useful information on the reliability of the three-step idealized-profile method. Those observations with $\mathrm{MH}_{\text {ceilometer }}$ much larger than $\mathrm{MH}_{\text {sounding }}$ were characterized by peaks in both the $\mathrm{STD}_{t}$ and the $\mathrm{STD}_{v}$ profiles lower than the evaluated $\mathrm{MH}_{\text {ceilometer. }}$ On the other hand, those observations with peaks in $\mathrm{STD}_{t}$ and the $\mathrm{STD}_{v}$ near $\mathrm{MH}_{\text {ceilometer }}$ had a high correlation with $\mathrm{MH}_{\text {sounding. }}$.

Our next goal is to test further the three-step idealizedprofile method with more data to better cover various weather situations, especially those with unstable ABLs. We also want to test the combination of the three-step method, the beginning of the longest continuous gradient, and the STD method to see if a combination of methods improves upon any single method.

Acknowledgments. Much of this work was supported by the European Research Council Grant 227915 (PBLPMES: Atmospheric Planetary Boundary Layers: Physics, Modelling and Role in Earth Systems). The Helsinki Testbed was funded by grants from the Finnish Technology and Innovation Agency (Tekes). The research leading to these results has also received funding from the European Union's Seventh Framework Programme FP/2007-2011 under Grant Agreement 212520 (MEGAPOLI-Megacities: Emissions, Urban, Regional and Global Atmospheric Pollution and Climate Effects, and Integrated Tools for Assessment and Mitigation). Author D. M. Schultz was partially funded by Vaisala Oyj.

\section{APPENDIX}

\section{Determination of the Entrainment Layer Depth}

Following the definition of entrainment layer, the backscattering coefficient at the top of the entrainment layer is $B_{\text {top }}=0.95 B_{u}+0.05 B_{m}$. Consequently, at the bottom of the entrainment layer, $B_{\text {bottom }}=0.05 B_{u}+$ $0.95 B_{m}$.

To find the height of the entrainment layer bottom, we insert $z=\mathrm{MH}-a \Delta h$ in Eq. (2). Thus, at the bottom of the entrainment layer,

$$
\begin{aligned}
B(\mathrm{MH}-a \Delta h)= & \frac{B_{m}+B_{u}}{2}-\frac{B_{m}-B_{u}}{2} \\
& \times \operatorname{erf}\left(\frac{\mathrm{MH}-a \Delta h-\mathrm{MH}}{\Delta h}\right) \\
= & 0.05 B_{u}+0.95 B_{m} .
\end{aligned}
$$

After some calculations, we receive $\operatorname{erf}(-a)=-0.9$. A table of error-function values reveals $a=1.17$.
Following the same procedure at the top of the entrainment layer, $z=\mathrm{MH}+b \Delta h$. Thus,

$$
\begin{aligned}
B(\mathrm{MH}+b \Delta h)= & \frac{B_{m}+B_{u}}{2}-\frac{B_{m}-B_{u}}{2} \\
& \times \operatorname{erf}\left(\frac{\mathrm{MH}-b \Delta h-\mathrm{MH}}{\Delta h}\right) \\
= & 0.95 B_{u}+0.05 B_{m},
\end{aligned}
$$

and consequently, $\operatorname{erf}(b)=0.9$. Thus, $b=a=1.17$, and $\mathrm{ELT}=2 a \Delta h=2.34 \Delta h$.

\section{REFERENCES}

Asimakopoulos, D. N., C. G. Helmis, and J. Michopoulos, 2004: Evaluation of sodar methods for the determination of the atmospheric boundary layer mixing height. Meteor. Atmos. Phys., 85, 85-92.

Beyrich, F., 1997: Mixing height estimation from sodar data-A critical discussion. Atmos. Environ., 31, 3941-3953.

Cohn, S. A., and W. M. Angevine, 2000: Boundary layer height and entrainment zone thickness measured by lidars and windprofiling radars. J. Appl. Meteor., 39, 1233-1247.

Emeis, S., C. Jahn, C. Münkel, C. Münsterer, and K. Schäfer, 2007: Multiple atmospheric layering and mixing-layer height in the Inn valley observed by remote sensing. Meteor. Z., 16, 415424.

Endlich, R. M., F. Ludwig, and E. E. Uthe, 1979: An automated method for determining the mixing depth from lidar observations. Atmos. Environ., 13, 1051-1056.

Eresmaa, N., A. Karppinen, S. M. Joffre, J. Räsänen, and H. Talvitie, 2006: Mixing height determination by ceilometer. Atmos. Chem. Phys., 6, 1485-1493.

Haeffelin, M., and Coauthors, 2011: Evaluation of mixing-height retrievals from automatic profiling lidars and ceilometers in view of future integrated networks in Europe. Bound.-Layer Meteor., 143, 49-75.

Hägeli, P., D. G. Steyn, and K. B. Strawbridge, 2000: Spatial and temporal variability of mixed-layer depth and entrainment zone thickness. Bound.-Layer Meteor., 97, 47-71.

Holzworth, C. G., 1964: Estimates of mean maximum mixing depths in the contiguous United States. Mon. Wea. Rev., 92, 235-242.

_ 1967: Mixing depths, wind speeds and air pollution potential for selected locations in the United States. J. Appl. Meteor., 6, 1039-1044.

Hooper, W. P., and E. Eloranta, 1986: Lidar measurements of wind in the planetary boundary layer: The method, accuracy and results from joint measurements with radiosonde and kytoon. J. Climate Appl. Meteor., 25, 990-1001.

Joffre, S. M., M. Kangas, M. Heikinheimo, and S. A. Kitaigorodskii, 2001: Variability of the stable and unstable atmospheric boundary-layer height and its scales over a boreal forest. Bound.-Layer Meteor., 99, 429-450.

Koskinen, J. T., and Coauthors, 2011: The Helsinki Testbed: A mesoscale measurement, research, and service platform. Bull. Amer. Meteor. Soc., 92, 325-342.

Münkel, C., 2007: Mixing height determination with lidar ceilometers-Results from Helsinki Testbed. Meteor. Z., 16, 451-459. 
_, and J. Räsänen, 2004: New optical concept for commercial lidar ceilometers scanning the boundary layer. Remote Sensing of Clouds and the Atmosphere IX, K. P. Schäfer et al., Eds., International Society for Optical Engineering (SPIE Proceedings, Vol. 5571), 364-374.

_ , N. Eresmaa, J. Räsänen, and A. Karppinen, 2007: Retrieval of mixing height and dust concentration with lidar ceilometer. Bound.-Layer Meteor., 124, 117-128.

Nelson, E., R. Stull, and E. Eloranta, 1989: A prognostic relationship for entrainment zone thickness. J. Appl. Meteor., 28, 885-903.

Seibert, P., F. Beyrich, S. E. Gryning, S. Joffre, A. Rasmussen, and P. Tercier, 2000: Review and intercomparison of the mixing height. Atmos. Environ., 34, 1001-1027.

Sicard, M., C. Pérez, F. Rocadenbosch, J. M. Baldasano, and D. GarcíaVizcaino, 2006: Mixed-layer depth determination in the Barcelona coastal area from regular lidar measurements: Methods, results and limitations. Bound.-Layer Meteor., 119, 135-157.

Steyn, D. G., M. Baldi, and R. M. Hoff, 1999: The detection of mixed layer depth and entrainment zone thickness from lidar backscatter profiles. J. Atmos. Oceanic Technol., 16, 953-959.

Strang, G., 2007: Computational Science and Engineering. WellesleyCambridge Press, 716 pp.

Vaisala, 2006: Vaisala ceilometer CL31 user's guide. Vaisala Oyj, $134 \mathrm{pp}$.

Vogelezang, D. H. P., and A. A. M. Holtslag, 1996: Evolution and model impacts of the alternative boundary layer formulations. Bound.-Layer Meteor., 81, 245-269.

Zilitinkevich, S., and A. Baklanov, 2002: Calculation of the height of the stable boundary layer in practical applications. Bound.Layer Meteor., 105, 389-409. 